\title{
Socially Integrated, Eco-Mimic Reversal of Global Warming
}

\author{
Bill Butterworth ${ }^{*}$
}

\author{
CEO, Land Network International Ltd, 15 Kingsmanor Wharf Devizes, SN10 2ES, UK
}

\begin{abstract}
The recent announcements of the IPCC [1] have indicated that many, indeed most, climatologists accept that climate change is happening, rapidly and the potential consequences are significant.

This paper examines the potential contribution to reduction and reversal of global warming by feeding the photosynthetic process with urban wastes, and how this can be integrated into existing or developable social structures in a way that allows normal economic drivers to produce rapid, large scale, sustainable results.
\end{abstract}

Keywords: Recycling, wastes, energy, photosynthesis, eco-mimic, socio-economic structures.

Technology can only benefit the human race if it can be developed and used within not only social and economic frameworks but in time to satisfy need. The Carboniferous Era began 360 million years ago and it took 60 million years to lay down global fossilised fuel reserves which, over a period of around 200 years, will be substantially burned up to produce Carbon dioxide and water. Both of these compounds not only affect climate but lock up the Oxygen on which most animal life depends. Reversing those effects certainly depends on developing productive technologies but these have to be affordable, workable within available social structures and be expandable rapidly. Most observers [1] see this as a race against time.

This paper, then, is about a search for a route to reverse global warming which was not only technically sound but could be organised globally and quickly. It began in early 1990's with 6 studies [2] commissioned under the Enterprise Initiative of the DTI of the British government. While these studies were confidential in detail relating to individual commercial operations, the general principles are releasable. The conclusions were based on two very clear concepts. Firstly, that reversal of global warming has been achieved before and very successfully (i.e. in the Carboniferous Era); why not mimic that mechanism? Secondly, there is a rough correlation between the wealth of a nation and the waste it produces. While it is reasonable to legitimately conclude that this correlation is something that contributes to global warming, it is also a saving grace; these wastes contain nutrients which will grow crops and many have organic molecules which lock up Carbon.

*Address correspondence to this author at the CEO, Land Network International Ltd, 15 Kingsmanor Wharf, Devizes, SN10 2ES, UK;

Tel: 01380 730413; Fax: 01380730413

E-mail bill@landnetwork.co.uk

\section{CHEMISTRY}

Figure 1 shows a basic equation of plants taking Carbon dioxide out of the atmosphere and water through their roots and produce small sugar molecules [3]. The most commonly quoted is the six-Carbon sugar molecule. When animals (including humans) use muscle energy, they push the equation the other way and we get the Carbon dioxide and water back. Keep those two equations in balance and we have long term sustainability.

The next line in the row of equations shows the burning of a small Carbon molecule, propane, and how much of each element is used up.

The final equation is the burning one of the large Carbon chain molecules actually found in petrol. This is what happens when a petrol-driven car is run.

Photosynthesis is exactly what happened on a global scale in the Carboniferous Era and the burning of fossilised fuels reverse it back again. So, why not just use the same process? We know it works and we know it can operate globally but we do not have 60 million years. Could enough be done to at least stabilise the global climate in, say, 100 years or preferably 50 ?

\section{THE MECHANISM OF "THE CLOSED LOOP”}

Figures 2 and 3 show how natural ecosystems manage to "leak" enough, and only enough, to keep the system working without pollution or starvation, i.e. in balance or "sustainably" [4]. Figure 2 shows a conventional view of how soluble nutrients are able to get into the plant. Although not incorrect, especially when referring to agriculture which uses mineral fertiliser, this description is incomplete and potentially misleading, especially if it were applied to soils with significant levels of organic matter and, particularly, 


\section{The basic equations in managing real sustainability}

Plants take $\mathrm{CO}_{2}$ and water $\stackrel{\text { Energy from the sun }}{\longrightarrow}$ To make large Carbon molecules

$$
\mathrm{CO}_{2}+\mathrm{H}_{2} \mathrm{O} \rightarrow \mathrm{C}_{6} \mathrm{H}_{12} \mathrm{O}_{6}
$$

$\longleftarrow$ Animals and incineration push this the other way

The balanced chemical equation reads;

$$
6 \mathrm{CO}_{2}+6 \mathrm{H}_{2} \mathrm{O} \rightarrow \mathrm{C}_{6} \mathrm{H}_{12} \mathrm{O}_{6}+6 \mathrm{O}_{2}
$$

Burning a small Carbon molecule reverses this process;

$\mathrm{C}_{3} \mathrm{H}_{8}+5 \mathrm{O}_{2} \rightarrow 3 \mathrm{CO}_{2}+\mathrm{H}_{2} \mathrm{O}$ - plus some energy as heat which we could use for making electricity Propane Oxygen

Burning a big Carbon molecule would read; One molecule from Petrol

$$
\begin{array}{ll}
\text { Rounded figures } & 2 \mathrm{C}_{36} \mathrm{H}_{74}+109 \mathrm{O}_{2} \rightarrow 72 \mathrm{CO}_{2}+74 \mathrm{H}_{2} \mathrm{O} \\
& 1 \text { tonne }+3.5 \text { tonnes } \rightarrow 3.2 \text { tonnes }+1.3 \text { tonnes }
\end{array}
$$

The green leaf can push this equation in the opposite direction

Figure 1:

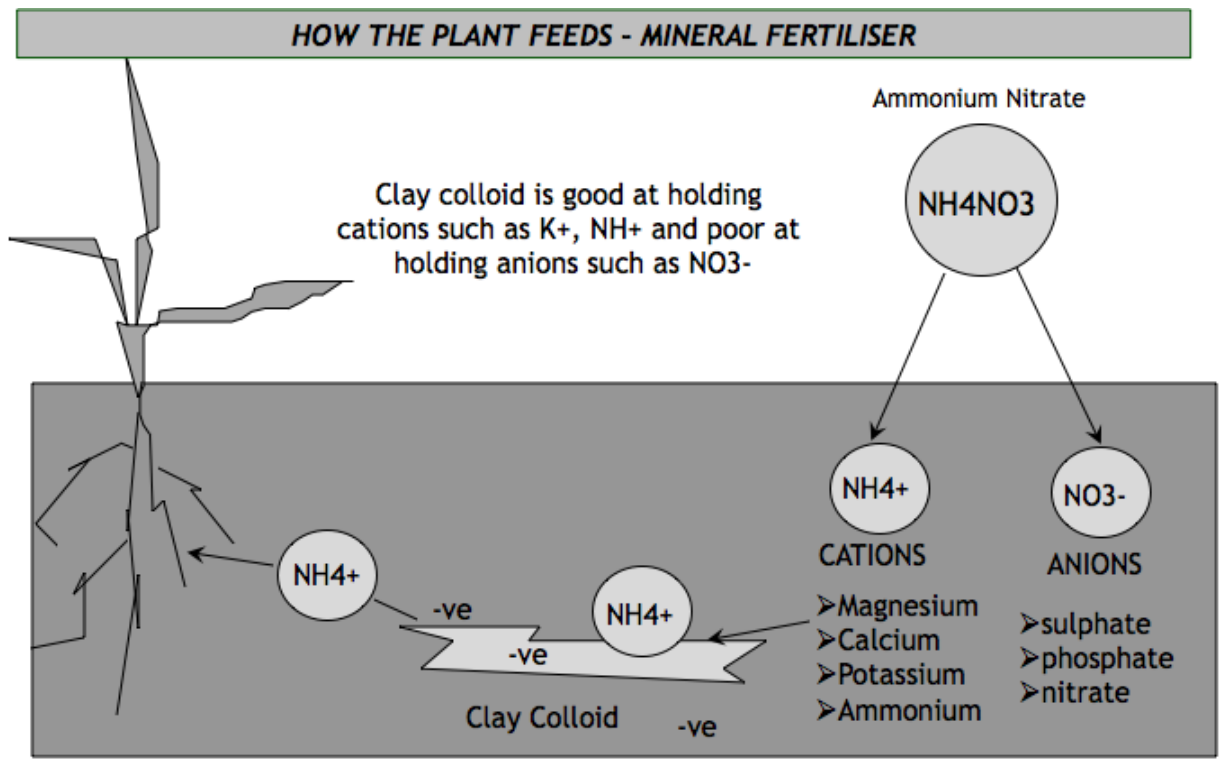

When mineral fertilisers such as Ammonium nitrate are applied, the cations are held in the soil colloid "bank" which also holds water. However, rain will take nearly half of the nitrate into groundwater.

Figure 2: The conventional view of how plants feed with the assumption that nutrients get to the plant via solution in the groundwater. With mineral fertilisers, this is probably either partly or completely true.

humus. Further, it does not explain why natural ecosystems don't leak enough to cause pollution. Figure 3 shows how such pollution is avoided and shows the mycorrhizal conduit which is the central mechanism in what is commonly referred to as "the closed loop" [3]. It is the mechanism which stops leakage at a level of pollution. It is this very same mechanism which feeds plants [5-7] and protects them from disease $[9,10]$. What this research showed was that this loop could be interrupted with a $3 \mathrm{~m}$ deep compost heap as in Figure 4.
Not only does this mechanism offer sustainable recycling to land, it also locks up Carbon in an organic sink [2]. Oxidation of this organic Carbon is accelerated by cultivations [8] but there are grades of stability in the complexity of molecules in soil humus. Current Research by a British university [11] shows that this stability may be manageable and, if so, improved. So, recycling wastes to land offers the chance of building a dynamic Carbon sink, i.e. exactly what occurred in the Carboniferous Era. 


\section{HOW THE PLANT FEEDS - NATURAL ECO-SYSTEM}

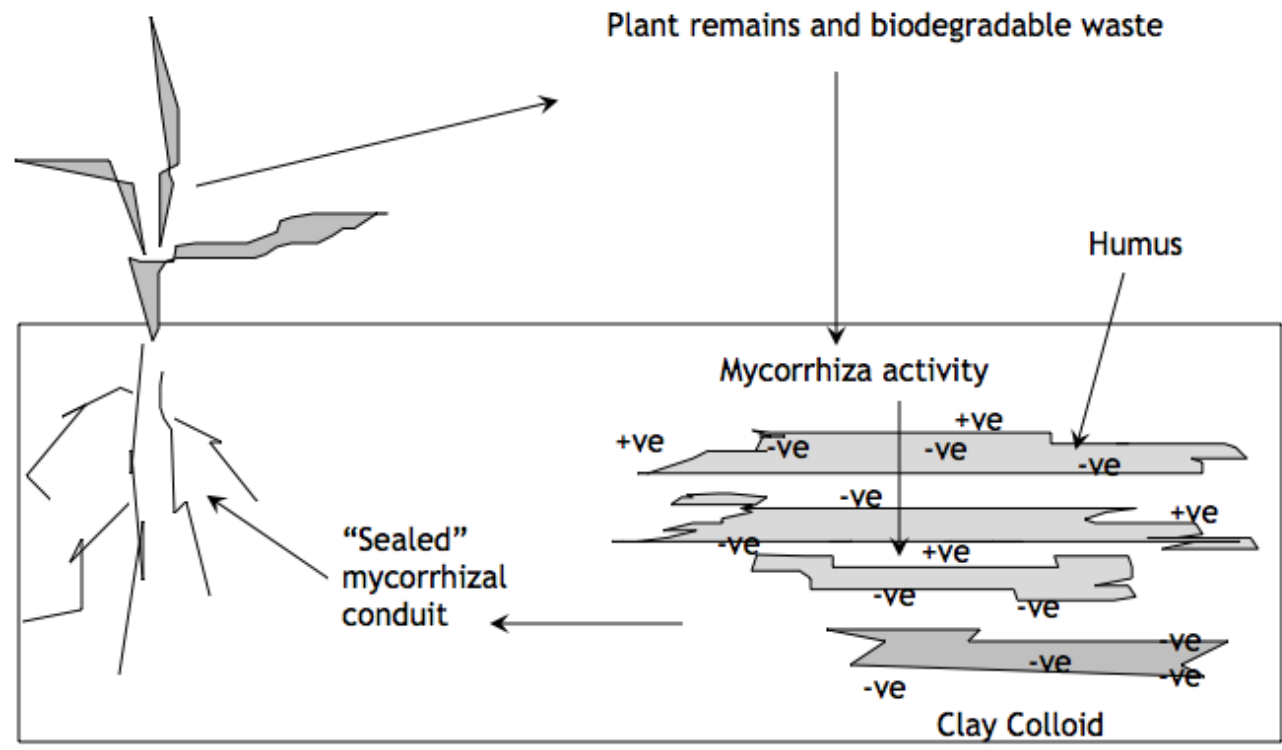

Mycorrhiza are the key to pollution control because they give a "Closed Loop" to recycling both cations and anions.

Figure 3: In natural ecosystems, plant nutrients do not enter into solution in the ground water in order to enter the plant. Humus is a complex mixture of heavy molecules which are not soluble in water. Neal Kinsey, in his book "Hands-on Agronomy", points out that this humus has several times the colloidal capacity of clay and will hold onto anions as well as cations. That, however, still did not explain how the nutrients got into the plant without leakage. It was the American PGA (Professional Golfers Association) who pursued this investigation to show that the soil fungi, known as mycorrhiza, fed at one end of their hyphae on the humus and the other end went not up to somewhere near the plant root hair but actually cross the root hair wall into the plant. This finding was added to by researchers at Aberystwyth in South Wales who showed that there was another type of mycorrhiza which went up to the root hair and wrapped around it much as the placenta in a mammal. This is a molecular level relationship and a closed conduit. That is why the natural ecosystems do not leak.

\section{HOW THE PLANT FEEDS - RECYCLING WASTE}

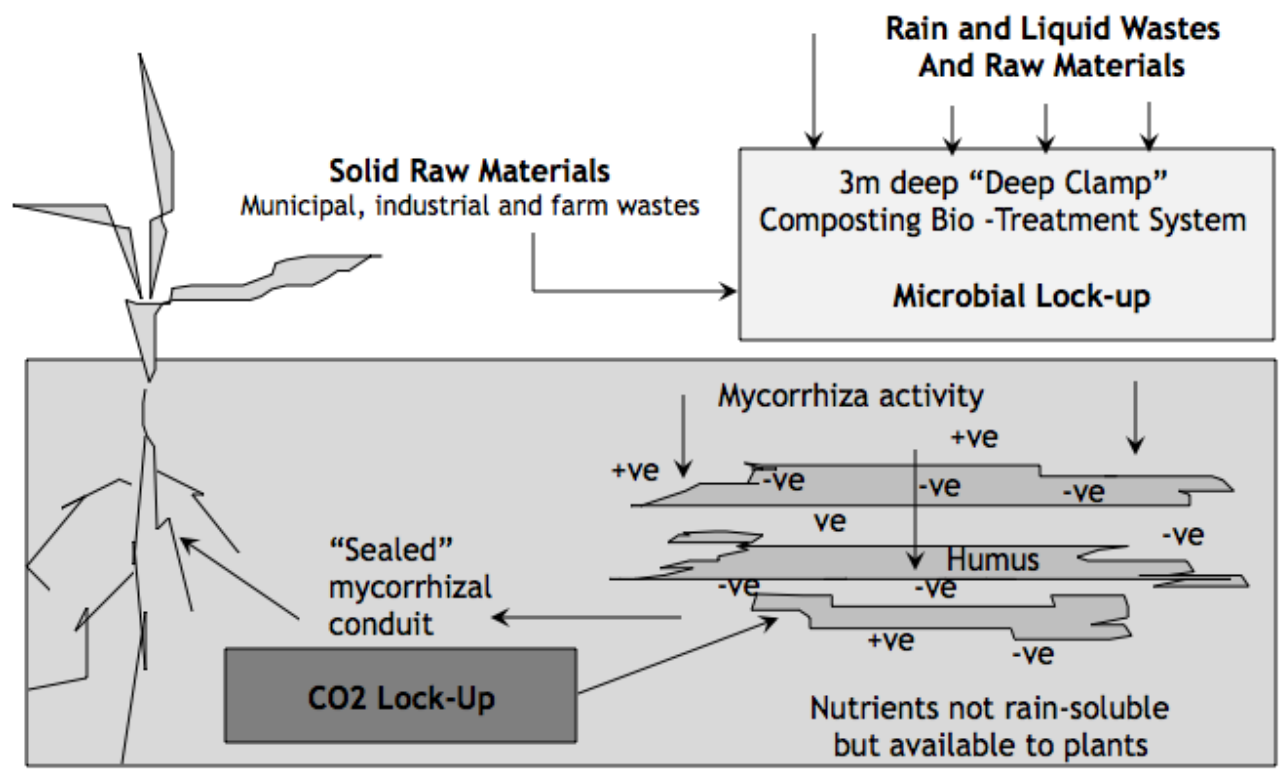

How the closed loop gives pollution control and scope for treatment systems.

Figure 4: What composting can do is provide a "buffer" between a controlled process and the soil. That buffer can isolate physical, chemical and biological risks in order to allow processing, monitoring and safety controls to operate. 


\section{MINERAL FERTILISERS}

According to research sponsored by the United Nations, one tonne of Nitrogen nutrient, delivered out of a typical, modern (reasonably efficient) factory in the USA, consumes $21,000 \mathrm{kWh}$ of electricity [12]. The global production of mineral Nitrogen fertiliser is now in the region of 100 to $150 \mathrm{mt}$ per annum. The electricity used in production comes mainly from burning fossilised fuel with an associated environmental cost. Farming with mineral fertilisers cannot be seen as environmentally sound.

\section{RECLAIMING DESERT AND GLOBAL CARBON DIOXIDE}

The implications of this work for the future imply two major opportunities can be tackled. Firstly, developing algae production to exploit using Photosynthetic Carbon Capture (PCC) is also fundamentally an ecomimic of the Carboniferous Era process and potentially a real, sustainable, solution to producing new energyrich fuels and plastics. Secondly, growing conventional farm crops and algae in the hot deserts would trap more energy from the sun; it would also take more Carbon dioxide out of the atmosphere and give more Oxygen back. If this were done using urban wastes through composting, which in itself provides a further Carbon sink, it could reduce irrigation requirements by up to a factor of 10 [13].

\section{CASH DRIVERS AND SOCIAL STRUCTURES}

Running parallel to this basic technical work in the UK, was development of a commercial structure, acceptable within established social frameworks. A franchise company was set up to offer a package of support to help farmers who owned land to compost a wide range of urban wastes [4], using the closed loop technology and with a franchise-supervised discipline. In turn, the farmers each owned a share of the franchisor; hence the term, "reverse franchise". Thus, an individual farmer lost no element of sovereignty but gained large scale, commercial, technical and legal support.

\section{RESULTS OF INTEGRATED "ECO-MIMIC" RECYCLING IN UK}

With the basis of creating a Carbon sink understood, an understanding and disciplined operation of recycling through the mechanism of The Closed Loop, and a socio-economic structure available, it was the introduction of a landfill tax in the UK that offered the economic "cash driver" which delivered real, on the ground results which can be multiplied up nationally and globally.

A 330 hectare farm in the Land Network farmers' group (Land Network Gainsborough) has delivered taking a range of municipal and industrial "wastes" to make compost, so eliminating the use of mineral fertilisers, to grow good crops safely and these include oil seed rape which is used, on the same farm, to produce biodiesel to EN14214. They calculate that taking 100 hectares of oil seed rape grown this way will produce enough energy to run a farm of 1000 hectares, including all the field work and all the houses of the families who work that land. If this farm had those 1000 hectares, the remaining 900 hectares would, with the soils on that farm, consistently produce 9,000 to 10,000 tonnes of wheat. So, farming without mineral fertilisers, based on recycling urban wastes, can be more productive. The farm has now been able to eliminate the use of mineral fertilisers on over $100 \%$ of their land. They have cut cultivation energy by over $60 \%$ and their yields have gone up and are more consistent, even in drought years. Interestingly, one of the farm staff noted that at the end of the dry summer of 2011, with the heavy clay soil baked close to brick hardness, there were significant numbers of mice making holes in the middle of fields. Red Kites were unknown in this area 10 years ago. Four were sighted that year; their main summer diet is mice.

Another farm in the Land Network group (Land Network Melton) does, again, use urban "wastes" to make compost to fertilise their land and eliminate groundwater pollution. One crop is oil seed rape which they crush to produce the oil (PPO - Pure Plant Oil) which they use to drive the farm's diesel engines. The River Eye runs through their 330 hectare (800 acre) farm and the two farming brothers are involved with the river authority including conservation of water voles, freshwater crayfish and otters, plus the RSPB with avian biodiversity (76 bird species and 18 butterfly species) on the whole of their farm. They grow several crops and the wheat they produce would make one million loaves of bread each year.

\section{CONCLUSIONS}

From early on in the development of this work, it was realised that the technology of composting and recycling to land (i.e. The Closed Loop mechanism) needed to be understood and, at the same time, that the use of that technology would only be successful if 
related to the skills and structure which existed in farming as an industry. As the work progressed, it became clear that the "reverse franchise" structure gave the independence and respect for sovereignty which each individual farmer wanted and enabled that farm to work in a larger organisation nationally, but also gave the discipline and organisation for the wider, national business to grow.

The gradual understanding of The Closed Loop allowed a parallel development of an increasing range of urban wastes to be safely recycled to farm land, largely on a proximity basis, and to the wider benefit of land including better soil moisture management with reduced crop drought stress, significantly less cultivation energy and a dramatic reduction in the use of mineral fertilisers.

The question of long term sustainability was, and remains, a key objective of this work. There is no doubt that this concern should be continually monitored. However, one indicator of long-term safety is the development of wildlife. The farm studies, operating as a "hands-on" bioassay, showed significant increases in biodiversity and populations over a ten year period. While there remain many questions of long-term safety, this biodiversity and population growth is a strong indicator that sustainability is possible and probable.

The reality of producing biofuels to the highest Standards from urban wastes raises many issues with respect to renewable energy production, proximity operation and getting trucks off the road, overall Carbon footprint, government responsibilities, and of course, global warming reduction. Nevertheless, this work does show that energy crops can be successfully and safely grown on land fertilised with urban wastes. There are two benefits from this in terms of reducing global warming. Firstly, the "wastes" are used rather than mineral fertilisers to produce energy crops; this has a very significant saving in energy use, especially with respect to producing mineral Nitrogen fertiliser. Secondly, building up soil organic matter acts as a very significant Carbon sink. Both these processes, directly or indirectly, take Carbon dioxide out of the atmosphere and return the Oxygen back to the atmosphere. In terms of energy production, this is certainly a significant matter for individual farmers and specific circumstances, but it is also potentially significant nationally, in any country in the world. At a national and international level, this then becomes a significant tool in global warming control and reduction. It is, in any case, a socially integrated mimic of the processes of the Carboniferous Era.

\section{ACKNOWLEDGEMENTS}

The author wishes to give credit to the many farmers who took part in this development of their farms and to the many thousands of preceding researchers, only some of whom are listed here under "References", on whose research this work depended in order to reduce risk.

\section{REFERENCES}

[1] Fifth Assessment Report (AR5), Intergovernmental Panel on Climate Change, Available from www.climatechange. 2013.org

[2] IF Research, Confidential reports by to the Enterprise Initiative of the DTI, British government 1992 to 1995.

[3] Butterworth B, Reversing Global Warming for Profit, MX Publishing, London 2009.

[4] Butterworth B, How to Make On-Farm Composting Work, MX Publishing, London 2009.

[5] Butterworth B, Clamping Down on Compost. Resource, American Society of Agricultural and Biological Engineers 2006; 13-14.

[6] Berg EB, et al. Plant litter, decomposition, humus formation, Carbon sequestration, Springer 2003.

[7] Kinsey N, Hands on agronomy, Acres USA 1999.

[8] Wright SF, Nichols KA, Soil Resource Management, ARS National Programme, Available from http://www.nps.ars. usda.gov

[9] Chaudhry TM, Biogeochemical characterization of Metalliferous wastes and potential of arbuscular mycorrhizae in their phytoremediation, School of Science, Food and Horticulture, College of Science, Technology and Environment, University of Western Sydney, Locked Bag 1797, Penrith South, DC NSW, Australia 1997.

[10] Jeffries $P$, The contribution of mycorrhizal fungi in sustainable maintenance of plant health and fertility. Biology Fertility of Soils 2003; 37: 1-16.

[11] Personal communication April 2014.

[12] Gellings C W and Parminter K E, Clark W. Gellings, Kelly E. Parmenter. Energy Efficiency in fertiliser production and use, in Efficient Use and Conservation of Energy, [Eds. Clark W. Gellings, and Kornelis Blok], Encyclopaedia of Life Support Systems (EOLSS), Developed under the Auspices of the UNESCO, Eolss Publishers, Oxford, UK 2004. [Available from http://www.eolss.net

[13] Butterworth B, A Top Idea That Holds Water, Water and Effluent Treatment News, 6 October 1999. 